\title{
Electronic tools for infectious diseases and microbiology
}

\author{
Steven D Burdette MD
}

\author{
SD Burdette. Electronic tools for infectious diseases and \\ microbiology. Can J Infect Dis Med Microbiol 2007;18(6):347- \\ 352.
}

Electronic tools for infectious diseases and medical microbiology have the ability to change the way the diagnosis and treatment of infectious diseases are approached. Medical information today has the ability to be dynamic, keeping up with the latest research or clinical issues, instead of being static and years behind, as many textbooks are. The ability to rapidly disseminate information around the world opens up the possibility of communicating with people thousands of miles away to quickly and efficiently learn about emerging infections. Electronic tools have expanded beyond the desktop computer and the Internet, and now include personal digital assistants and other portable devices such as cellular phones. These pocket-sized devices have the ability to provide access to clinical information at the point of care. New electronic tools include e-mail listservs, electronic drug databases and search engines that allow focused clinical questions. The goal of the present article is to provide an overview of how electronic tools can impact infectious diseases and microbiology, while providing links and resources to allow users to maximize their efficiency in accessing this information. Links to the mentioned Web sites and programs are provided along with other useful electronic tools.

Key Words: Electronic tools; ID Web sites; Internet; PDAs; Smartphone

Clectronic tools for infectious diseases and medical microbiEology have the ability to change the way we approach the diagnosis and treatment of infectious diseases and public health. Medical information today can be dynamic, keeping up with the latest research or clinical issues, instead of being static and years behind, as many textbooks are. The ability to rapidly disseminate information around the world opens up the possibility of communicating with people thousands of miles away to learn quickly and efficiently about emerging infections. Increased world travel has also increased the potential for spreading infectious diseases from one side of the world to the other in a very short time, making the utility of electronic tools imperative today.

Electronic tools have expanded beyond the desktop (or even laptop) computer and the Internet. There are numerous computer-based software programs that are essential for physicians and microbiologists (1). Personal digital assistants (PDAs) have the ability to provide access to clinically relevant information at the point of care (2). These portable electronic devices are essentially mini-computers. The Windows-based Pocket PC (Microsoft Corporation, USA) or the Palm OS (Palm Inc, USA) are the two dominant platforms in regard to access to medical applications. Differentiating between the Pocket PC and the Palm OS is beyond the scope of the present article, but the differences between today's devices are minor.

\section{Les technologies de l'information au service de l'infectiologie et de la microbiologie}

Les technologies de l'information appliquées à l'infectiologie et à la microbiologie médicale ont le pouvoir de changer notre façon d'aborder le diagnostic et le traitement des maladies infectieuses. De nos jours, l'information médicale peut être dynamique, et nous permet d'être au courant des recherches ou des problématiques cliniques les plus récentes, comparativement aux ouvrages imprimés, qui sont statiques et datent parfois de plusieurs années. La capacité de transmettre rapidement l'information partout dans le monde nous permet de communiquer avec des gens qui se trouvent à des milliers de kilomètres de distance et de nous renseigner rapidement et efficacement au sujet des infections émergentes. La technologie de l'information ne se limite plus aux ordinateurs de bureau et à l'Internet, elle englobe aussi les assistants numériques et autres appareils portables, comme le téléphone cellulaire. Ces appareils de poche nous donnent désormais accès à des informations cliniques au chevet même des malades. Parmi les nouveaux outils électroniques, mentionnons Listserv, les bases de données électroniques sur les médicaments et les moteurs de recherche qui permettent de raffiner les interrogations. Le présent article a pour but de dresser un tableau d'ensemble de l'impact que peuvent avoir les nouvelles technologies de l'information sur l'infectiologie et la microbiologie, tout en suggérant des liens et des ressources qui rendront les utilisateurs plus performants dans leurs quête d'information. Au fur et à mesure, l'auteur fournit au lecteur des liens vers les sites et les programmes Web mentionnés en cours de route, de même que des suggestions d'outils électroniques utiles.

Most popular medical software is available for both operating systems. Combination cellular phones and PDAs are also available. The Treo (Palm Inc) (currently using Microsoft Windows Mobile 5.0 Pocket PC or Palm OS) is perhaps the best known, although there are numerous brands now available depending on the cellular provider. Combined phone and PDAs limit the number of devices a person carries and, therefore, potentially provide increased convenience. Smartphones (Microsoft Corporation) (many using Microsoft Windows Mobile 5.0 or 6.0) and Blackberry devices (Research in Motion, Canada), while providing Internet access and day planner functions, currently lack substantial medical software, but this is anticipated to improve with time.

Web-based handheld technology is highly effective for supplying information to support infectious disease clinical practice. Bochicchio et al (3) evaluated the clinical utility of the Johns Hopkins Antibiotic Guide (www.hopkins-abxguide.org) installed on a PDA. In a hospital intensive care setting, results of this study demonstrated that physician knowledge and antibiotic decision selection accuracy improved among users of the PDAbased antibiotic guide. Honeybourne et al (4) evaluated handheld technology as an effective clinical tool to aid evidence-based practice and support the educational needs of clinical staff (4). The authors concluded that PDAs can provide a critical mass of information that is relevant, quickly accessible and in a

Wright State University Boonshoft School of Medicine, Dayton, Ohio, USA

Correspondence: Dr Steven D Burdette, Wright State University Boonshoft School of Medicine, 128 East Apple Street, CHE Building 2nd Floor,

Dayton, Ohio 45409, USA. Telephone 937-208-2873, fax 937-208-2621, e-mail Steve.burdette@wright.edu

Received and accepted for publication September 7, 2007 
coherent format - delivering clinical information at the point of need with a resulting benefit to patient safety. We have previously evaluated several infectious diseases applications and found that a majority of infectious diseases syndromes encountered within the hospital setting can have treatment recommendations guided by the PDA (5).

Google (www.google.com) has developed into a popular means of acquiring information in today's electronic society, much to the disdain of medical librarians. Many physicians 'google' a topic to attempt to seek rapid answers to clinical questions. While often successful, one must be wary of obtaining clinical opinions or information that is blatantly incorrect. While MEDLINE remains the ideal means by which to review medical literature, users should be familiar with Google Scholar. Google Scholar covers peer-reviewed papers, theses, books, abstracts and other scholarly literature. Google images can provide photographs of commonly encountered Gram stains, cultures and other useful images to assist both microbiologists and infectious disease practitioners.

The goal of the present manuscript is to provide an overview of how electronic tools can impact infectious diseases and medical microbiology, while providing links and resources to allow users to maximize their efficiency in accessing this information. Links to the mentioned Web sites and programs are provided in Table 1, along with other useful electronic tools.

\section{A DAY IN THE LIFE OF AN INFECTIOUS DISEASE PRACTITIONER}

\section{6:00}

After beginning the day with a cup of coffee, you sit down to catch up on the latest infectious diseases situations around the world. After reviewing the latest e-mailed table of contents from your favorite journals, you spend a few minutes reviewing other references to keep up-to-date on the latest infectious disease issues.

\section{THE EMERGING INFECTIONS NETWORK AND PROGRAM FOR MONITORING EMERGING DISEASES}

The Emerging Infections Network (EIN) has operated since 1996, and has become a network of infectious diseases consultants who respond to surveys about emerging infectious diseases and also spontaneously provide information about emerging infectious diseases observed in their clinical practices. Members of the Infectious Diseases Society of America (IDSA), the IDSA leadership, and the Pediatric Infectious Diseases Society, Centers for Disease Control and Prevention investigators, and other members of the public health community are eligible to join. The EIN communicates to its members via a listserv, sending frequent e-mails to keep members informed. The EIN gathers relevant clinical data that complement other surveillance systems. It has demonstrated that it can respond quickly to urgent problems and that it can facilitate communication between its members and the public health community. Recent postings have included breaking news on a previously rare infection acquired by travellers, clinical questions on patient isolation with multidrug-resistant organisms and issues with overprescribing of antibiotics for viral syndromes. The organization also recently gathered data regarding an increased prevalence and severity of Clostridium difficile-associated diarrhea, and has impacted surveillance performed by many health departments.
The Program for Monitoring Emerging Diseases is an Internet-based reporting system dedicated to rapid global dissemination of information on outbreaks of infectious diseases and acute exposures to toxins that affect human health (6). By providing early warning of outbreaks of emerging and re-emerging diseases, public health precautions at all levels can be taken in a timely manner to prevent epidemic transmission. Sources of information include media reports, official reports, online summaries, local observers and others. A central purpose of the program is to promote communication among the international infectious disease community, including scientists, physicians, epidemiologists, public health professionals and others interested in infectious diseases on a global scale.

\section{ClinMicroNet}

ClinMicroNet, sponsored by the American Society of Microbiology, is a closed Internet discussion group in which doctoral level clinical microbiologists from many countries share their knowledge and experience to promote better professional practice and greater understanding of practical problems. Recent queries have requested information on how laboratories perform methicillin-resistant Staphylococcus aureus (MRSA) surveillance, issues with automated susceptibility testing with newer antibiotics, difficult Gram stain images, as well as job openings and upcoming educational meetings. The American Society of Microbiology keeps a searchable database of all the topics (by subject line), which allows users to review previously posted discussions.

Empirical evidence shows that ClinMicroNet is more than an Internet discussion list. It complements other existing resources by encouraging members to share experiences and collaborate in establishing best practices (7).

\section{INFECTIOUS DISEASE NEWS}

A commonly utilized reference that many physicians and clinical microbiologists use to quickly review the latest medical literature. Available online with e-mail newswire, subscribers can use a free e-mail service to keep abreast of the latest research in a rapidly changing field. Tools such as this allow readers to be abreast of hot issues without having to subscribe to numerous journals.

\section{8:00}

The first patient of the day arrives in the office. A 55-year-old man complains of cough with productive sputum and shortness of breath. The chest radiograph reveals a right lower lobe pneumonia. Remembering that the new guidelines for community-acquired pneumonia were recently released, you excuse yourself from the room to review the guidelines before advising therapy.

\section{IDSA - PRACTICE GUIDELINES}

The IDSA makes available the published guidelines on a variety of infectious disease conditions on their Web site, free of charge or membership. Practice guidelines are systematically developed statements to assist practitioners and patients in making decisions about appropriate health care for specific clinical circumstances. Within these evidence-based guidelines are background information and extensive treatment recommendations. Treatments are typically provided in table format to allow expedited access to the necessary clinical information. Recently released guidelines include recommendations on community-acquired pneumonia, antimicrobial resistance and nontuberculous mycobacterial disease treatment. 
TABLE 1

Suggested Web sites and downloads for infectious diseases and medical microbiology

\begin{tabular}{|c|c|c|c|}
\hline Type & Name & Web site & Formats \\
\hline \multirow[t]{3}{*}{ E-mail services } & ClinMicroNet & <mail.asmusa.org/read/all_forums $>$ & www, e-mail \\
\hline & Emerging Infections Network & $<w w w . i d s o c i e t y . o r g>$ & www, e-mail \\
\hline & Program for Monitoring Emerging Diseases & $<w w w$.fas.org/promed $>$ & www, e-mail \\
\hline $\begin{array}{l}\text { PDA and cellular } \\
\text { phone software }\end{array}$ & Epocrates & $<$ www.epocrates.com> & $\begin{array}{l}\text { www, PPC, Palm OS, SP } \\
\text { BB }\end{array}$ \\
\hline \multirow[t]{6}{*}{ Windows Mobile } & Johns Hopkins Antibiotic Guide & <hopkins-abxguide.org> & www, Palm OS \\
\hline & Lexi-Comp & $<$ www.lexi.com> & PPC, Palm OS, BB \\
\hline & Sanford Guide & $<$ www.sanfordguide.com> & www, Palm OS, PPC, BB \\
\hline & Shots 2007 & $<w w w . i m m u n i z a t i o n e d . o r g>$ & www, Palm OS, PPC \\
\hline & Skyscape & $<w w w . s k y s c a p e . c o m>$ & $\begin{array}{l}\text { PPC, Palm OS, BB, SP } \\
\text { iPhone }\end{array}$ \\
\hline & UpToDate & $<w w w . u p t o d a t e . c o m>$ & www, PPC, Palm OS \\
\hline \multirow[t]{6}{*}{ PDA Web sites } & CollectiveMed & $<$ www.collectivemed.com/pda $>$ & www, PPC, Palm OS \\
\hline & Ectopic Brain & <pbrain.hypermart.net> & www, Palm OS \\
\hline & Medical Pocket PC & $<w w w . m e d i c a l p o c k e t p c . c o m>$ & www, PPC \\
\hline & Palmdoc Chronicles & <palmdoc.net/> & www, PPC, Palm OS \\
\hline & Palmgear & $<w w w \cdot p a l m g e a r . c o m>$ & www, Palm OS \\
\hline & PocketGear & $<w w w \cdot p o c k e t g e a r . c o m>$ & www, PPC \\
\hline \multirow[t]{7}{*}{ Canadian Web sites } & Association of Medical Microbiology and Infectious Diseases Canada & $<$ www.ammi.ca $>$ & www \\
\hline & Canadian Association for Clinical Microbiology and Infectious Diseases & $<$ www.cacmid.ca $>$ & www \\
\hline & Canadian Committee on Antibiotic Resistance & $<$ www.ccar-ccra.com> & www \\
\hline & Canadian Foundation for Infectious Diseases & $<w w w . r e s e a r c h i d . c o m>$ & www \\
\hline & $\begin{array}{l}\text { Canadian Institutes of Health Research - } \\
\text { Institute of Infection and Immunity }\end{array}$ & $<$ cihr-irsc.gc.ca> & www \\
\hline & Canadian Journal of Infectious Diseases \& Medical Microbiology & $<$ www.pulsus.com/Infdis $>$ & www \\
\hline & Health Canada & $<w w w \cdot h c-s c . g c . c a>$ & www \\
\hline \multirow[t]{14}{*}{ Web sites } & American Society of Microbiology & $<w w w . a s m . o r g>$ & www, e-mail \\
\hline & Antimicrobe.org & $<w w w . a n t i m i c r o b e . o r g>$ & www \\
\hline & Doctor Fungus & $<$ www.doctorfungus.org $>$ & www \\
\hline & Emerging Infectious Diseases & $<$ www.cdc.gov/ncidod/EID> & www \\
\hline & European Society of Clinical Microbiology and Infectious Diseases & $<$ www.escmid.org $>$ & www \\
\hline & Gideon & $<$ www.gideononline.com> & www \\
\hline & Google Scholar & <scholar.google.com> & www \\
\hline & Infectious Disease News & $<$ www.infectiousdiseasenews.com> & www, e-mail \\
\hline & Infectious Diseases Society of America & $<w w w . i d s o c i e t y . o r g>$ & www, e-mail \\
\hline & National Foundation for Infectious Diseases & $<$ www.nfid.org $>$ & www \\
\hline & National Guideline Clearinghouse & $<$ www.guidelines.gov> & www \\
\hline & National Institute of Allergy and Infectious Diseases & $<w w w 3 . n i a i d . n i h . g o v>$ & www \\
\hline & National Network for Immunization Information & $<w w w$.immunizationinfo.org $>$ & www \\
\hline & World Health Organization & $<$ www.who.int $>$ & www \\
\hline
\end{tabular}

BB Blackberry (Research in Motion, Canada); PDA Personal digital assistant; PPC Pocket PC (Microsoft Corporation, USA); SP Smartphone; www World wide web. Palm OS is manufactured by Palm Inc, USA

Recommendations on prosthetic joint infections, $\mathrm{C}$ difficileassociated diarrhea and encephalitis, among others, are due to be released in 2008. Many of the guidelines are also available to be downloaded directly to the PDA.

Based on the guidelines, you advise that the patient should be treated with moxifloxacin, but he is concerned about a potential drug-drug interaction with metoprolol (Lopressor, Novartis Pharmaceuticals, USA). You take out your PDA and perform a quick search of moxifloxacin drug interactions (Figure 1).

\section{Epocrates}

There are various medication and antibiotic guides that are available for both the Palm OS and the Pocket PC. Perhaps the most popular of the drug references is Epocrates (Eprocrates Inc, USA). Offering both free and subscription downloads, Epocrates is a drug database with an extensive list of medications (including antimicrobial agents). Within the software, users find dosing recommendations, adverse events, drug-drug interactions and pharmacology information, as well as routine information previously difficult to obtain (including cost). Epocrates, with a recently released version for mobile phones, also provides access to selected textbooks and other unique attachments to increase the breadth of information that can be accessed.

One essential feature of Epocrates is MultiCheck. With this, users can select multiple medications, and the software searches its database to identify potential drug-drug interactions. This 


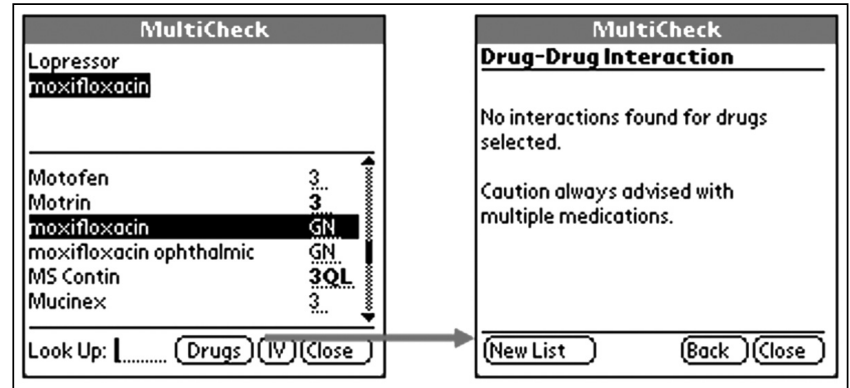

Figure 1) Epocrates MultiCheck revealing no drug interactions between moxifloxacin and Lopressor (Novartis Pharmaceuticals, USA). Reproduced with permission from Epocrates Inc (USA)

may impact the initial decision of antibiotic therapy and advise patients on whether potential side effects may be related to drug interactions. Before the advent of this type of software (now available from other software manufacturers), this would have been very tedious to do by using a textbook or other print reference.

\section{0:00}

A long-term HIV patient comes in for a follow-up. During the discussion, the patient asks whether he or she should receive the herpes zoster vaccination. You are unsure so you seek further information from the program 'Shots 2007'.

\section{SHOTS 2007}

Shots 2007 (The Group on Immunization Education of the Society of Teachers of Family Medicine, USA) is available for multiple platforms. It is a reference to the 2007 Childhood Immunization Schedule and the 2006-2007 Adult Immunization Schedule (8), recommended by the Advisory Committee on Immunization Practices. This software provides a vast amount of information on standard vaccinations that clinicians encounter routinely but does not cover some of the travel-related vaccinations (ie, typhoid). Provided is standard timing of vaccination recommendations, adverse reactions, contraindications, route of administration, catch-up information and high-risk indications. Many versions include photos of the clinical manifestations that the vaccines are intended to prevent.

\section{1:00}

A new consult arrives in the office with recurrent MRSA subcutaneous abscesses. You recall having heard about new guidelines from the Association of Medical Microbiology and Infectious Disease (AMMI) Canada regarding MRSA, so you slip out of the room to quickly review the information.

\section{AMMI CANADA AND HEALTH CANADA}

The AMMI Canada Web site provides access to an extensive amount of resources. Within The Canadian Journal of Infectious Diseases $\mathbb{E}$ Medical Microbiology, subscribers are able to access previous articles in portable document format (PDF) in addition to accessing the special supplements on topics such as community-associated MRSA and Canadian patterns of antimicrobial resistance. The AMMI Canada Web site also provides access to previous conference lectures in PDF format, in addition to published abstracts from the meeting.

Health Canada is the federal department responsible for helping Canadians maintain and improve their health. Their

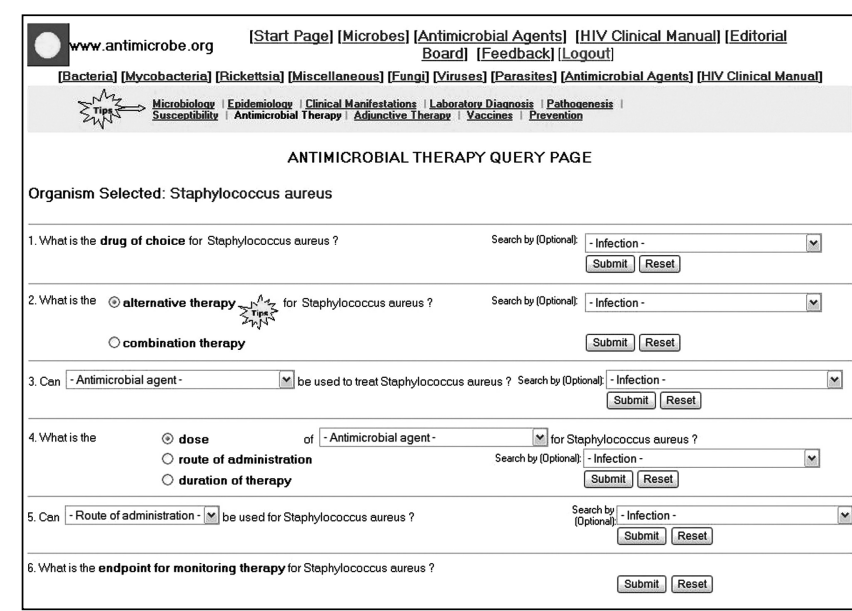

Figure 2) Antimicrobe.org's smart search, which allows users to seek answers to very specific clinical questions. Reproduced with permission from Antimicrobe.org

Web site provides information on advisories, warnings and recalls, while providing clinical information on a variety of diseases and conditions. For health care providers, the 'Diseases \& Conditions' link provides a significant amount of clinical data, including links and resources for the most commonly encountered infectious diseases, with a clinical slant toward communicable disease.

\section{2:00}

The final outpatient of the day is a 45-year-old man with AIDS. He was seen earlier in the week for a headache and is back for follow-up. Before seeing the patient, you find that he has a positive serum cryptococcal antigen. You seek treatment options before entering the room.

\section{ANTIMICROBE.ORG}

Antimicrobe.org is the interactive online site that currently hosts four textbooks, with further site expansion anticipated in the future (9). Volume 1: Microbes is a review of commonly and uncommonly encountered pathogens. The majority of the textbook is focused on treatment options for the various pathogens, although the background and clinical information is expanding. Volume 2: Antimicrobial Agents is an exhaustive review of available antimicrobial drugs. Available in the online format is a PDF file for each of the drugs, which provides a onepage overview so that the physician can have quick and ready access while on the go. The site also provides an HIV manual as guidance for both the experienced and inexperience HIV practitioner. Currently in the works is Empiric, a guide to various infectious disease syndromes.

Multiple means of searching for clinical information are provided within the site. Unique to Antimicrobe.org is the smart search (Figure 2). It is based on matching a pathogen with one of 10 subjects. This search engine allows for specific clinical questions to be addressed with focused answers, taking away the need to read entire paragraphs. The provided 'hits' from the smart search also links to a 'Guided MEDLINE Search'. Using the same clinical queries that were entered in the MYCIN search, engine users are routed to PubMed, which provides topic-focused references limited to the previous three years that are constructed as would be done by an experienced medical librarian. 
Free access to Antimicrobe.org is available on a short-term basis. Users can enter the username 'ammi' and the password 'ammi' to have full access.

\section{JOHNS HOPKINS ANTIBIOTIC GUIDE}

The Johns Hopkins Antibiotic Guide is an online reference also available for the Palm OS. Provided within this guide is background, diagnostic and treatment modalities of various infectious diseases. The guide is broken down by organ system, pathogens and antibiotics. For example, when treating a patient for pneumonia, users review current treatment recommendations, see a list of the most common pathogens and the recommendations for routine clinical evaluation. If a clinician is evaluating a patient with staphylococcal bacteremia, information is available regarding common sites of infection, clinical manifestations of infection and other pertinent data. The drug section provides pertinent clinical information regarding dosing, side effects and other information. One unique function of this guide is the 'author opinion' option. Within this link, users can select a certain therapeutic regimen for a disease and the guide provides access to the author's opinion of the regimen. This may provide a 'curbside' consult when making treatment decisions is challenging. This software is currently offered free of charge.

\section{UpToDate}

UpToDate.com is a well-known, comprehensive, online medical reference. This textbook, while not specifically an infectious diseases manual, addresses a majority of infectious diseases conditions. Basic microbiology is not the focus of this clinical text. Several years ago, a Pocket PC version was released for no additional charge and the Palm OS devices are now also supported. Their software now allows users to have nearly the entire UpTo Date reference available at all times.

Searching UpToDate begins by entering a single-word query. The reference then provides a detailed list of matches to the single term. Users are then required to select the topic that most closely approximates their desired clinical questions. From this second tier of links, users can select the chapter that most likely provides them with their answer. When viewing the chapter, a detailed table of contents is provided to help limit the amount of reading. UpToDate provides access to the guidelines published by the IDSA for the treatment of infectious disease conditions.

\section{4:00}

While making hospital rounds, a neutropenic patient has a blood culture positive for Fusarium species. You seek electronic assistance in making your treatment decisions.

\section{THE SANFORD GUIDE}

The Sanford Guide to Antimicrobial Therapy is one of the most recognized resources for the treatment of infectious diseases; classically, it is a paperback manual that fits in a user's pocket. This guide is now available for the Palm OS, the Pocket PC and the Blackberry (http://www.sanfordguide.com). The focus of the Sanford Guide is therapy; therefore, minimal data are provided in regard to clinical evaluation of diseases or syndromes. The available information is identical to the paperback version; however, the electronic format requires a significant amount of use to become comfortable with accessing information and may, at times, be more time consuming than using the paperback version.

\begin{abstract}
TABLE 2
Recommendations to maximize your time and financial efficiency when approaching electronic tools for infectious diseases and medical microbiology

Recommendations
Purchase software only if a free trial period is provided
Do not give up if initially frustrated with electronic tools
Talk to colleagues to determine which programs they find useful
Utilize reviews and message boards before purchasing software
Identify three to five programs or Web sites and master them
Do not expect to become an expert, or even efficient, in a short amount
of time
Use a PDA for calendar and contacts, as well as clinical information
Do not read lengthy texts on a PDA
Purchase the warranty options for electronic devices
\end{abstract}

PDA Personal digital assistant

\section{DOCTOR FUNGUS}

There are many mycology references on the Web (10), but Doctor Fungus (www.doctorfungus.org) is a free-access Web site dedicated to providing information on mycology. Content ranges from basic microbiology to treatment recommendations; the amount of data available is extensive. The site includes a comprehensive image database (basic and clinical images) and free lecture downloads, along with an enormous amount of other clinical information. One less utilized feature is susceptibility testing data. The query is interactive and the user sets their limitations; on completion, a focused review of available susceptibility information is provided.

\section{CONCLUSIONS}

Electronic tools have the ability to be of real benefit to the busy clinician and microbiologist. The ability to access timely recommendations and clinical literature allows the best treatment or diagnostic options to be provided to patients. The dynamic nature of electronic information, compared with static printed texts, makes use of electronic tools increasingly essential in modern medicine. No longer are long walks to the library, or digging through stacks of journals or medical textbooks necessary. Information is available at your fingertips; the PDA can be accessible in your pocket even when out to dinner with friends. However, technology does have its drawbacks.

The learning curve in becoming familiar with the resources takes time and energy. Users do not become fluent with the available resources after only a few hours. This time requirement often leads to frustration and the temptation to 'do it the old fashioned way'. The financial investment for purchasing online textbooks or programs can be significant, as can the cost of maintaining a computer or a PDA. But the potential time saved by utilizing these references is worth it. Users are also advised to take advantage of free trial periods for sites or software before purchasing them. Most software developers that believe in their software provide a one- to two-week freeof-charge trial period. Table 2 provides a list of recommendations to help to maximize time and efficiency during the transition period to becoming an electronic tools user. When it comes to technology, be patient - everyone can learn to be a 'techie' even without having a pocket protector. 


\section{Burdette}

\section{REFERENCES}

1. Magos A, Mehta R, Tsimpanakos I. Ten pieces of software every doctor should have. Lancet 2007;369:464.

2. Miller SM, Beattie MM, Butt AA. Personal digital assistant infectious diseases applications for health care professionals.

Clin Infect Dis 2003;36:1018-29.

3. Bochicchio GV, Smit PA, Moore R, et al. Pilot study of a web-based antibiotic decision management guide. J Am Coll Surg 2006;202:459-67.

4. Honeybourne C, Sutton S, Ward L. Knowledge in the palm of your hands: PDAs in the clinical setting. Health Info Libr J 2006;23:51-9.

5. Burdette SD, Herchline TE, Richardson WS. Killing bugs at the bedside: A prospective hospital survey of how frequently personal digital assistants provide expert recommendations in the treatment of infectious diseases. Ann Clin Microbiol Antimicrob 2004;3:22.
6. Madoff LC. ProMED-mail: An early warning system for emerging diseases. Clin Infect Dis 2004;39:227-32.

7. Dwyer V. ClinMicroNet - sharing experiences and building knowledge virtually. Clin Microbiol News 2004;25:121-5.

8. Centers for Disease Control and Prevention. General recommendations on immunization: Recommendations of the Advisory Committee on Immunization Practices (ACIP). $<$ http://www.cdc.gov/mmwr/preview/mmwrhtml/rr5515al.htm> (Version current at October 12, 2007).

9. Burdette SD, Herchline TE. Antimicrobe.org: An online reference for the practicing infectious diseases specialist. Clin Infect Dis 2006;43:765-9. (Erratum in 2006;43:1088).

10. Cortez KJ, Groll AH, Walsh TJ. Resources for medical mycology on the World Wide Web. Clin Infect Dis 2005;40:437-50. 


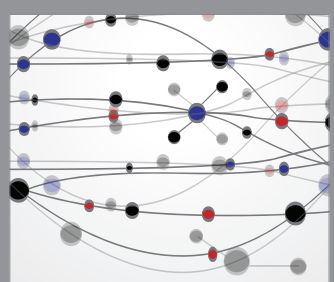

The Scientific World Journal
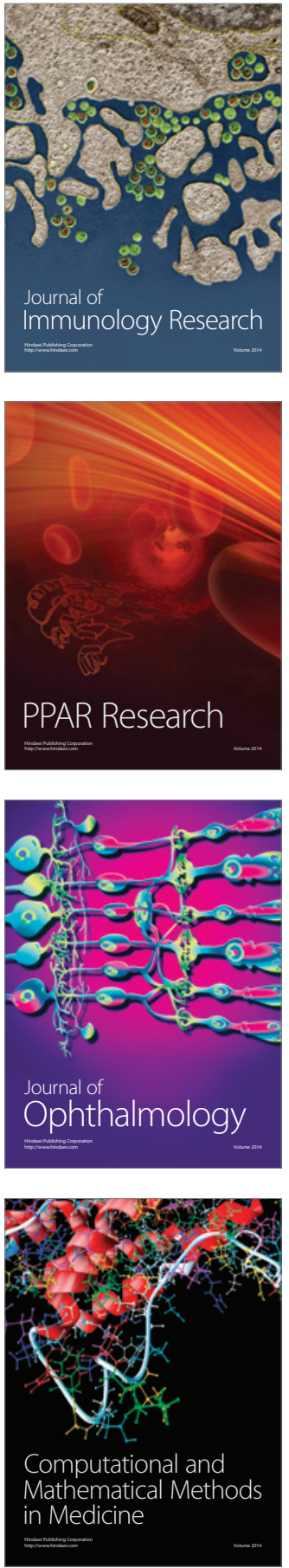

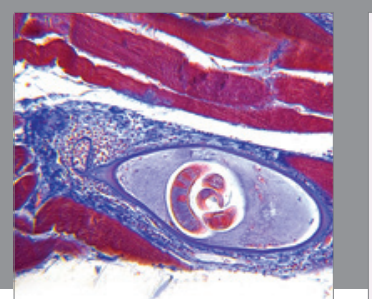

Gastroenterology Research and Practice

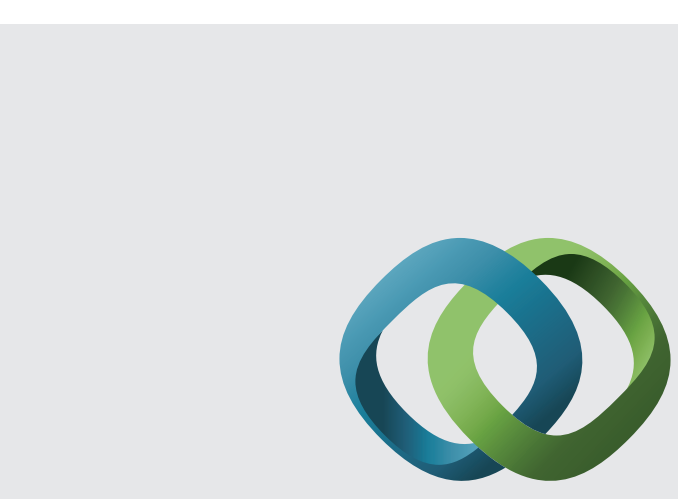

\section{Hindawi}

Submit your manuscripts at

http://www.hindawi.com
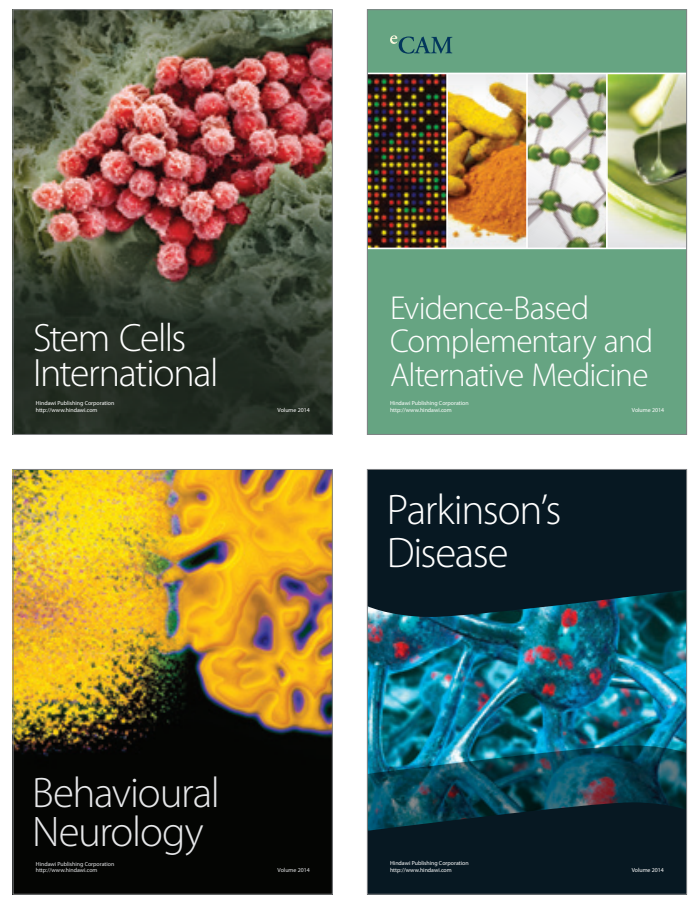
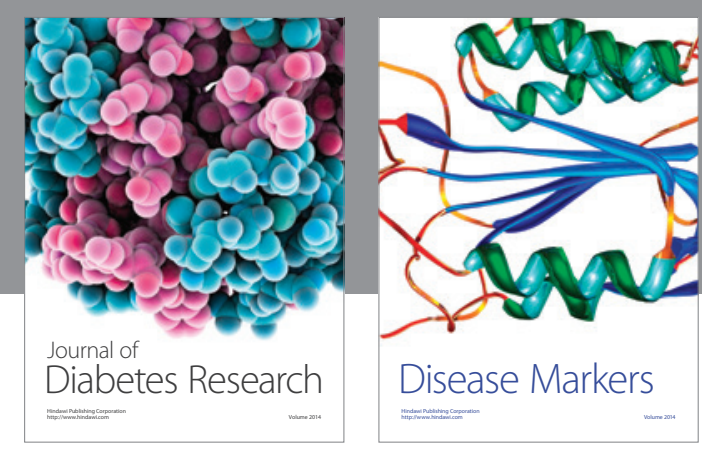

Disease Markers
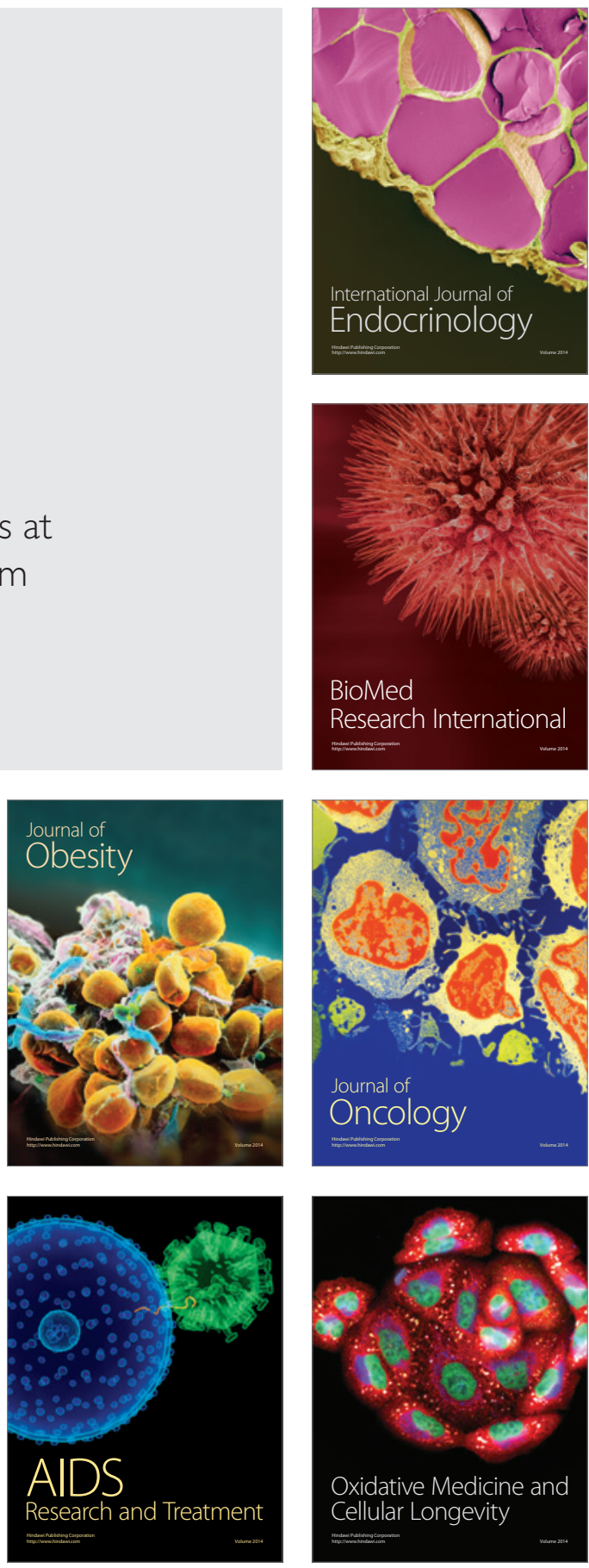